\title{
Brief Exercise Enhances Blood Hypocretin-1 in Sedentary Men
}

\section{Giovanni Messina, Giovanni Di Bernardo, Antonietta Messina, Carmine Dalia, Sergio Chieffi, Umberto Galderisi and Marcellino Monda*}

Department of Experimental Medicine, Section of Human Physiology and Clinical Unit of Dietetics and Sports Medicine, Second University of Naples, Naples, Italy

\begin{abstract}
The aim of this experiment was to test the effect of brief exercise on the concentration of plasma hypocretin-1, a peptide that regulates many physiological variables. Blood samples were collected from participants $(m e n, n=6)$ before (time $0 \mathrm{~min}$ ) and after (times 15 and $30 \mathrm{~min}$ ) a cycle ergo meter exercise at $75 \mathrm{~W}$ for $15 \mathrm{~min}$. The physical exertion was monitored by heart rate registration. The exercise causes a significant increase in plasmatic hypocretin-1, in association with an increase of hearth rate. These results are the first demonstration, which indicates that plasma hypocretin- 1 is involved in the reactions induced by physical activity.
\end{abstract}

Keywords: Hypocretin-1; Exercisel; Heart rate

\section{Introduction}

The hypothalamic neuropeptide "hypocretin-1" [1] is also named orexin-A for itsinfluence on food intake[2,3]. An intracerebroventricular injection of hypocretin-1 does not merely affects food intake, but it also causes an increase in heart rate (HR) [4], blood pressure [5], and metabolic rate [6]. These autonomic modifications indicate that this neuropeptide plays a role in the control of vegetative functions. Hypocretin-1 also affects thermoregulation, including changes in "core" temperature and temperature of interscapular brown adipose tissue (IBAT) $[7,8]$.

The presence of hypocretin receptors in many cerebral areas indicates that several functions are played by hypocretin-1 [9]. Some antipsychotic drugs, as haloperidol, clozapine, risperidone, and quetiapine, modify the sympathetic and hyperthermic reactions due to hypocretin-1 [10-13]. A role for the hypocretin-1 in sleep regulation has been demonstrated [14]. Deficiency in hypocretin-1 causes narcolepsy in mice, cats, dogs, and humans [15-18]. Studies in rodents have indicated that hypocretin-1 crucial for the regulation of respiration [19-22].

Since there are few studies concerning the modification of plasmatic hypocretin-1 in humans and, in particular, there is no study during exercise, the aim of the present research was to investigate the effect of exercise on the concentration of plasma hypocretin-1. This experiment could reveal a role for hypocretin-1 in the reactions induced by physical activity.

\section{Methods}

\section{Subjects}

Six male sedentary were enrolled among those who contacted the Clinical Unit of Dietetics and Sports Medicine of the Second University of Naples. Age and anthropometric values, expressed as mean \pm standard error (SE) are reported in Table 1.

\section{Ethics statement}

The experimental procedures followed the rule approved by Ethic Committee of the Second University of Naples. Patients were informed on the research and permission for the use of plasma samples was obtained. All procedures were conforming to the directives of the Declaration of Helsinki.

\begin{tabular}{|c|c|}
\hline Age (Years) & $23.7 \pm 3.12$ \\
\hline BMI $\left(\mathrm{Kg} / \mathrm{m}^{2}\right)$ & $20.09 \pm 1.9$ \\
\hline
\end{tabular}

Table 1: Age, Body mass index (BMI) of subjects.

\section{Study protocol}

The study protocol consisted of one day of testing in which each participant was asked to continue his normal work and leisure activities. The subjects were instructed to consume food and beverages as usual and to sleep a sufficient amount of hours. The period of experiment was divided in 3 times: resting time $(0 \mathrm{~min})$, exercise time $(1-15 \mathrm{~min})$ and recovery time (16-30 $\mathrm{min})$. Three blood samples were collected in all periods of experiment. One sample at resting time, one sample at last min of exercise, and one sample at recovery time. The physical activity consisted in a cycle ergometer exercise at $75 \mathrm{~W}$ for $15 \mathrm{~min}$, performed at 1-15 min period. All tests were performed in laboratory environment with a normal ambient climate.

\section{Measurement of HR}

After standard adjustments of seat and handlebar, the participants cycled on a calibrated mechanically braked cycle ergometer (Kettler ergometer E7) at $75 \mathrm{~W}$, with no stop for 15 minutes. HR data were recorded during all period of experiment. Each participant wore a chest belt hard-wired to a digital R-R recorder (BTL08 SD ECG), where the QRS-signal wave-form R-R signal was sampled at the resolution of $1 \mathrm{~ms}$. The HR (beats min-1) was calculated according to the following formula: $\mathrm{HR}=60 \mathrm{R}-\mathrm{R}$ interval-1; where, R-R interval was converted into seconds.

\section{Plasma hypocretin-1 detection}

Blood samples were collected from all participants in the study. Blood samples were drawn from forearm vein at 8:00 a.m. after overnight fast into Vacutainer tubes (BD, Franklin Lakes, NJ) containing EDTA and $0.45 \mathrm{TIU} / \mathrm{ml}$ of aprotinin. Samples were gently mixed and then immediately centrifuged at $3000 \mathrm{rpm}$ for $12 \mathrm{~min}$ at $4{ }^{\circ} \mathrm{C}$. Plasma was stored at $-80^{\circ} \mathrm{C}$ until analysis. Plasma hypocretin- 1 levels were measured using commercially available enzyme-linked immunoassay (ELISA) kits. Hypocretin-1 ELISA kit was purchased from Phoenix Pharmaceuticals. Before measurement, plasma hypocretin-1 was extracted using Sep-Pak C18 columns (Waters, Milford, MA). The columns were activated using

*Corresponding author: Marcellino Monda, Professor, Department of Experimental Medicine, Second University of Naples, via Costantinopoli, 16 I-80138 Naples, Italy; Tel: +39-0815665804; Fax: +39 0815665841; E-mail: marcellino.monda@unina2.it

Received August 28, 2014; Accepted November 03, 2014; Published November 10,2014

Citation: Messina G, Di Bernardo G, Messina A, Dalia C, Chieffi S, et al. (2014) Brief Exercise Enhances Blood Hypocretin-1 in Sedentary Men. J Sports Med Doping Stud 4: 149. doi:10.4172/2161-0673.1000149

Copyright: ( $) 2014$ Messina G, et al. This is an open-access article distributed under the terms of the Creative Commons Attribution License, which permits unrestricted use, distribution, and reproduction in any medium, provided the original author and source are credited. 
$10 \mathrm{ml}$ of methanol and $20 \mathrm{ml}$ of H2O. 1-2 $\mathrm{ml}$ of sample was applied to the column and washed with $20 \mathrm{ml}$ of water. Samples were eluted slowly with $80 \%$ acetonitrile and resulting volume was reduced to 400 $\mu \mathrm{l}$ under nitrogen flow. Aliquot was further evaporated into dryness using Speedvac (Savant Instruments, Holbrook, NY). The dry residue was dissolved in water and used for ELISA. There was no crossreactivity of the antibody for hypocretin-1(16-33), hypocretin-2, agouti-related protein(83-132)-amide. The minimal detectable concentration was 0.37 $\mathrm{ng} / \mathrm{ml}$, the intra-assay error $<5 \%$ and the inter-assay error $<14 \%$.

\section{Statistical analysis}

The values are presented as means $\pm \mathrm{SE}$, Statistical analysis was performed using analysis of variance. Multiple comparisons were performed by the Newman-Keuls post hoc test. All data were analyzed with GraphPad Prism-version 5.01 statistical software package (GraphPad, CA, USA).

\section{Control group}

Three subjects without any exercise were used as controls. HR and hypocretin-1 were monitored as exercising subjects.

\section{Results}

Figure 1 illustrates the modification of the HR. Exercise induced an increase in HR. The analysis of variance showed significant effects [F $(2,15)=87.42, \mathrm{p}<0.01]$. The post-hoc test showed a difference between pre-exercise and post-exercise values.

Figure 2 shows changes in blood concentration of hypocretin-1.

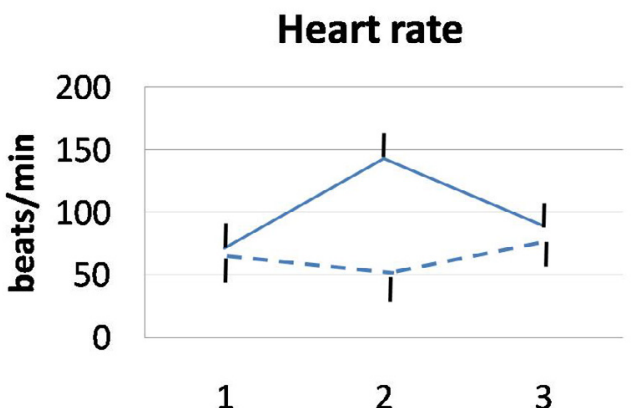

Figure 1: Changes in heart rate during resting (time 1), exercise (time 2), and recovery (time 3 ).

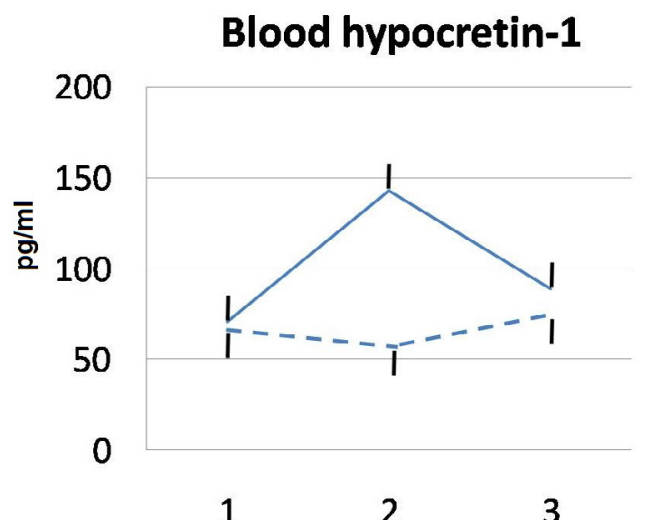

Figure 2: Changes in hypocretin-1 during resting (time 1), exercise (time 2), and recovery (time 3 ).
The physical activity caused an increase in hypocretin- 1 . The analysis of variance showed significant effects $[\mathrm{F}(2,15)=22.24, \mathrm{p}<0.01]$. The posthoc test showed a difference between pre-exercise and post exercise values.

In the control group, HR and hypocretin-1 level did not modify during the times of the experiment. The data are not reported in the figures.

\section{Discussion}

This experiment is the first demonstration showing an increase of plasmatic hypocretin-1 during exercise in humans. The values of hypocretin-1 concentration are plausible with published reports. The peripheral origin of hypocretin-1 is not well known. The pancreatic beta-cells are retained secretor cells of hypocretin-1. Double immunohistochemical staining, using a polyclonal anti-insulin antibody, showed that hypocretin-1 is co-expressed with insulin [23]. In our experiment, the increase of plasmatic hypocretin-1 probably is due to an increase in the secretion of hypocretin- 1 by pancreatic beta-cells. Since the sympathetic nervous system is involved in the regulation of pancreatic hormonal secretion [24], an enhancement of the sympathetic discharge of nerves to pancreas could increase the secretion of hypocretin-1.

Exercise is associated to the sympathetic activation, as demonstrated by increase in HR. Exercise elicits adaptive responses to sustain muscle engagement. Physical activity induces not only the sympathetic activation, but also hormonal changes $[25,26]$. The increase in plasmatic hypocretin-1 could be included among hormonal adaptations due to exercise. Plasmatic hypocretin-1 could be involved in the control of cortisol secretion. Indeed, relationship between hypocretin-1 and cortisol has been described. Since hypocretin-1 increases the expression of steroidogenic enzymes in human adrenocortical cells [27], an influence of hypocretin-1 on cortisol secretion (enhanced during physical activity) is conceivable. In further studies, determination of plasma insulin and cortisol levels will be measured using the present experimental design.

In the present experiment, the sympathetic discharge is positively associated with level of plasmatic hypocretin-1. Muscle exercise induces an increase in HR, controlled by the sympathetic nervous system, which is accompanied by an increase in plasmatic hypocretin-1, as demonstrated by the findings of the present experiment. Although it is well established that cerebral hypocretin-1 is related to the sympathetic discharge, the results of our research are the first ones showing an association between the plasmatic hypocretin-1 and HR, as expression of the sympathetic activity. An intracerebral injection of hypocretin-1 causes a generalized increase in the sympathetic discharge with augmented firing rate of sympathetic fibers innervating interscapular brown adipose tissue [28,29] heart [30], kidneys [31], etc. Studies in rodents have concluded that hypocretin neurons have a major role in the regulation of HR. Intracisternal hypocretin administration increases HR and blood pressure [32-34] and microinjections into the nucleus of the solitary tract elicit dose dependent changes in HR and blood pressure.

These evidences suggest that cerebral hypocretinergic pathway controls the sympathetic nervous system with possible relationship of "cause-effect" between hypocretin-1 and sympathetic activation. Although the findings of the present experiment do not indicate a secure "cause-effect" relationship, but only an association, it is very possible that hypocretin-1 could influence the sympathetic activity and/ or vice-versa. Since hypocretin-1 rapidly enters brain from blood by 
simple diffusion [35], it is possible that increased plasmatic hypocretin1during exercise time could induce cerebral stimulation of areas that, in turn, control the sympathetic reactions.

In a broader vision of the physiological role of hypocretin-1, the benefits of physical activity [36] in the control of body weight could include an increased peripheral secretion of this peptide. Since hypocretin-1 is involved in the regulation of body weight $[37,38]$, and in the patho-physiology of obesity, an increased secretion of plasmatic hypocretin-1during physical activity, as showed in this experiment, could influence body weight probably through an activation of energy expenditure [39]. The findings of this experiment shed further light on the positive effects of exercise, including hypothetic positive effect exerted by plasmatic hypocretin-1.

In conclusion, our study represents the first demonstration that the exercise induces an increase in plasmatic hypocretin- 1 and this peptide could play an important role in the peripheral adaptations to physical activity.

\section{Acknowledgements}

The present work received financial support from the Postgraduate School in Sports Medicine of the Second University of Naples (process numbers 2013/13-0).

\section{Competing Interest}

The authors declare that they have no competing interests.

\section{References}

1. de Lecea L1, Kilduff TS, Peyron C, Gao X, Foye PE, et al. (1998) The hypocretins: hypothalamus-specific peptides with neuroexcitatory activity. Proc Natl Acad Sci U S A 95: 322-327.

2. Sakurai T, Amemiya A, Ishii M, Matsuzaki I, Chemelli RM, et al. (1998) Orexins and orexin receptors: a family of hypothalamic neuropeptides and $G$ proteincoupled receptors that regulate feeding behavior. Cell 92: 573-585.

3. Monda M1, Viggiano A, De Luca V (2003) Paradoxical [correction of parodoxical] effect of orexin A: hypophagia induced by hyperthermia. Brain Res 961: $220-228$

4. Monda M1, Viggiano AN, Viggiano A, Viggiano E, Lanza A, et al. (2005) Hyperthermic reactions induced by orexin $A$ : role of the ventromedial hypothalamus. Eur J Neurosci 22: 1169-1175.

5. Shirasaka T1, Nakazato M, Matsukura S, Takasaki M, Kannan H (1999) Sympathetic and cardiovascular actions of orexins in conscious rats. Am J Physiol 277: R1780-1785.

6. Lubkin M1, Stricker-Krongrad A (1998) Independent feeding and metabolic actions of orexins in mice. Biochem Biophys Res Commun 253: 241-245.

7. Monda M1, Viggiano A, Mondola P, De Luca V (2001) Inhibition of prostaglandin synthesis reduces hyperthermic reactions induced by hypocretin-1/orexin $A$ Brain Res 909: 68-74.

8. Monda M1, Viggiano A, Viggiano A, Fuccio F, De Luca V (2004) Injection of orexin A into the diagonal band of Broca induces sympathetic and hyperthermic reactions. Brain Res 1018: 265-271.

9. Kukkonen JP1, Holmqvist T, Ammoun S, Akerman KE (2002) Functions of the orexinergic/hypocretinergic system. Am J Physiol Cell Physiol 283: C15671591.

10. Monda M, Viggiano A, De Luca V (2003) Haloperidol reduces the sympathetic and thermogenic activation induced by orexin A. Neurosci Res 45: 17-23.

11. Monda M1, Viggiano A, Viggiano A, Fuccio F, De Luca V (2004) Clozapine blocks sympathetic and thermogenic reactions induced by orexin $A$ in rat. Physiol Res 53: 507-513.

12. Monda M1, Viggiano A, Viggiano A, Viggiano E, Messina G, et al. (2006) Quetiapine lowers sympathetic and hyperthermic reactions due to cerebral injection of orexin A. Neuropeptides 40: 357-363.

13. Monda M1, Viggiano A, Viggiano A, Viggiano E, De Luca V (2006) Risperidone potentiates the sympathetic and hyperthermic reactions induced by orexin $A$ in the rat. Physiol Res 55: 73-78.
14. Beuckmann CT1, Yanagisawa M (2002) Orexins: from neuropeptides to energy homeostasis and sleep/wake regulation. J Mol Med (Berl) 80: 329-342.

15. Kiyashchenko LI1, Mileykovskiy BY, Maidment N, Lam HA, Wu MF, et al. (2002) Release of hypocretin (orexin) during waking and sleep states. J Neurosci 22 5282-5286.

16. Taheri S1, Zeitzer JM, Mignot E (2002) The role of hypocretins (orexins) in sleep regulation and narcolepsy. Annu Rev Neurosci 25: 283-313.

17. Wu MF1, John J, Maidment N, Lam HA, Siegel JM (2002) Hypocretin release in normal and narcoleptic dogs after food and sleep deprivation, eating, and movement. Am J Physiol Regul Integr Comp Physiol 283: R1079-1086.

18. Zhang S1, Lin L, Kaur S, Thankachan S, Blanco-Centurion C, et al. (2007) The development of hypocretin (orexin) deficiency in hypocretin/ataxin-3 transgenic rats. Neuroscience 148: 34-43.

19. Zhang W1, Fukuda Y, Kuwaki T (2005) Respiratory and cardiovascular actions of orexin-A in mice. Neurosci Lett 385: 131-136.

20. Zhang W, Zhang N, Sakurai T, Kuwaki T (2009) Orexin neurons in the hypothalamus mediate cardiorespiratory responses induced by disinhibition of the amygdala and bed nucleus of the stria terminalis. Brain Res 1262: 25-37.

21. Corcoran A1, Richerson G, Harris M (2010) Modulation of respiratory activity by hypocretin-1 (orexin A) in situ and in vitro. Adv Exp Med Biol 669: 109-113.

22. Terada J1, Nakamura A, Zhang W, Yanagisawa M, Kuriyama T, et al. (2008) Ventilatory long-term facilitation in mice can be observed during both sleep and wake periods and depends on orexin. J Appl Physiol (1985) 104: 499-507.

23. Dall'Aglio C1, Pedini V, Scocco P, Boiti C, Ceccarelli P (2010) Immunohistochemical evidence of Orexin-A in the pancreatic beta cells of domestic animals. Res Vet Sci 89: 147-149.

24. Thorens B (2010) Central control of glucose homeostasis: the brain--endocrine pancreas axis. Diabetes Metab 36 Suppl 3: S45-49.

25. Messina G, Vicidomini C, Viggiano A, Tafuri D, Cozza V, et al. (2012) Enhanced parasympathetic activity of sportive women is paradoxically associated to enhanced resting energy expenditure. Auton Neurosci 169: 102-106.

26. Viggiano A, Vicidomini C, Monda M, Carleo D, Carleo R, et al. (2009) Fas and low-cost analysis of heart rate variability reveals vegetative alterations in noncomplicated diabetic patients. J Diabetes Complications 23: 119-123.

27. Wenzel J1, Grabinski N, Knopp CA, Dendorfer A, Ramanjaneya M, et al (2009) Hypocretin/orexin increases the expression of steroidogenic enzymes in human adrenocortical NCI H295R cells. Am J Physiol Regul Integr Comp Physiol 297: R1601-1609.

28. Monda M1, Viggiano A, Viggiano A, Viggiano E, Messina G, et al. (2007) Sympathetic and hyperthermic reactions by orexin $A$ : role of cerebral catecholaminergic neurons. Regul Pept 139: 39-44.

29. Monda M1, Sullo A, De Luca E, Pellicano MP (1996) Lysine acetylsalicylate modifies aphagia and thermogenic changes induced by lateral hypothalamic lesion. Am J Physiol 271: R1638-1642.

30. Shahid IZ1, Rahman AA, Pilowsky PM (2012) Orexin and central regulation of cardiorespiratory system. Vitam Horm 89: 159-184.

31. Tanida M1, Niijima A, Shen J, Yamada S, Sawai H, et al. (2006) Dose-different effects of orexin-A on the renal sympathetic nerve and blood pressure in urethane-anesthetized rats. Exp Biol Med (Maywood) 231: 1616-1625.

32. Hirota K1, Kushikata T, Kudo M, Kudo T, Smart D, et al. (2003) Effects of centra hypocretin-1 administration on hemodynamic responses in young-adult and middle-aged rats. Brain Res 981: 143-150.

33. Jochem J1, Zwirska-Korczala K, Zabielski R, Kato I, Kuwahara A (2006) Cardiovascular effects of centrally acting orexin A in haemorrhage-shocked rats. J Physiol Pharmacol 57 Suppl 11: 115-124

34. Huang SC, Dai YW, Lee YH, Chiou LC, Hwang LL (2010) Orexins depolarize rostral ventrolateral medulla neurons and increase arterial pressure and heart rate in rats mainly via orexin 2 receptors. J Pharmacol Exp Ther 334: 522-529.

35. Kastin AJ1, Akerstrom V (1999) Orexin A but not orexin B rapidly enters brain from blood by simple diffusion. J Pharmacol Exp Ther 289: 219-223.

36. Garland TJr, Schutz H, Chappell MA, Keeney BK, Meek TH et al. (2011) The biological control of voluntary exercise, spontaneous physical activity and daily energy expenditure in relation to obesity: human and rodent perspectives. J Exp Biol 15: 206-229. 
Citation: Messina G, Di Bernardo G, Messina A, Dalia C, Chieffi S, et al. (2014) Brief Exercise Enhances Blood Hypocretin-1 in Sedentary Men. J Sports Med Doping Stud 4: 149. doi:10.4172/2161-0673.1000149

37. Boughton CK1, Murphy KG (2013) Can neuropeptides treat obesity? A review of neuropeptides and their potential role in the treatment of obesity. $\mathrm{Br} J$ Pharmacol 170: 1333-1348

38. Perez-Leighton CE, Boland K, Teske JA, Billington C, Kotz CM (2012) Behavioral responses to orexin, orexin receptor gene expression, and spontaneous physical activity contribute to individual sensitivity to obesity. Am J Physiol 303: E865-E874.

39. Panossian LA1, Veasey SC (2012) Daytime sleepiness in obesity: mechanisms beyond obstructive sleep apnea--a review. Sleep 35: 605-615. 